\title{
Evaluation of structural intervention in the Quartel das Esquadras, Almeida (Portugal)
}

\author{
L.F. Ramos \\ ISISE, University of Minho, Guimarães, Portugal \\ A.C. Núñez García \\ Old Structures Engineering. PC, New York, USA \\ F.M. Fernandes \\ ISISE, University of Lusiada, Famalicão, Portugal \\ P.B. Lourenço \\ ISISE, University of Minho, Guimarães, Portugal
}

\begin{abstract}
The Quartel das Esquadras is an 18th century infantry barrack located within the limits of the bulwarked fortress of Almeida, in Portugal. An ongoing adaptive reuse project of the building aims to recover its full capacity and also its importance to the fortified village of Almeida, by implementing a variety of new uses. While adaptive reuse projects of historical buildings are a very recommendable solution for maintaining those constructions whose use has become obsolete, these projects demand careful study because they may introduce changes in the structural behaviour of the buildings to preserve.

The architectural intervention results in the need of the structure to withstand new and diverse imposed loads, as well as inserting passages and communication systems to enable a proper contemporary use of the building, fulfilling architectural requirements and current building codes. As the current configuration of the structure will be altered, the main objective of this paper is to evaluate the suitability of some of the proposed structural interventions. Such evaluation requires a good understanding of the current state of the structure and the alterations proposed by the project. The current condition has been characterized following a multidisciplinary approach comprising historical research, visual inspection, non-destructive testing and structural analysis. The alterations proposed by the project have been described, identifying possible sources of major structural problems. A portion of the building particularly affected by the alterations has been selected to carry out structural analysis. A comparative safety assessment of the selected area in both current and altered condition has been done through finite element modelling and nonlinear static analysis, resulting in an identification of the weaker points against the new implemented loads and alterations. Finally, proposals for the implementation of the studied intervention, as well as recommendations for future research and analyses, have been given.
\end{abstract}

\section{INTRODUCTION}

\subsection{Motivation}

The Quartel das Esquadras is a unique example of early 18th century military barracks placed in the fortified village of Almeida, location of great relevance in the historical border between Portugal and Spain, which is currently running to be recognized as UNESCO World Heritage together with other bulwarked fortifications along the border. Most of the spaces enclosed in the barracks are currently unused and showing deterioration, reason for which the municipality aims to recover the importance and full capacity of the building by promoting an adaptive reuse of its spaces. An architectural intervention has been designed in order to reintroduce uses back into the building, which has been proven to be the best way of guaranteeing maintenance, crucial for structural integrity, of historic buildings whose use has become obsolete.

The architectural intervention requires such implementations that some structural elements will have to be removed or modified, altering the current configuration of the structure.

The aim of the present paper is to present the procedure that has been followed in order to evaluate the structural intervention by means of analysing the current condition of the structure of the building as well as the expected structural performance after the proposed architectural interventions.

\subsection{Methodology}

The evaluation process has been done by means of a wide and interdisciplinary scientific approach, 
comprising historical research, visual inspection, nondestructive testing and structural analysis.

Firstly, historical research was carried out to understand the original configuration of the building as well as any possible alterations experienced, to formulate initial hypotheses regarding the characteristics of the structural elements, and to plan in a more efficient way the later performed survey campaign.

Afterwards, the current condition of the building was portrayed by means of a survey campaign carried out in May, 2015, in which visual inspections and non-destructive testing were combined to better characterize the structure.

Finally, the influence of the intervention in the structural behaviour of the Quartel das Esquadras was carried out by means of a comparative safety analysis of a selected area of the structure in both current and altered conditions.

\subsection{Description of the building}

The Quartel das Esquadras has suffered several alterations since its construction, but no major alteration in its structural configuration has been performed (Núñez García, 2015). The building still stands isolated within the urban layout, and no additional levels have been added to the construction. The structure is $106.5 \mathrm{~m}$ long, $15.8 \mathrm{~m}$ wide and $11.2 \mathrm{~m}$ high.

The main structural system is composed by two levels of 21 adjoining vaulted units, protected by a hipped roof supported by a timber structure. The first floor had to be completely reconstructed after being severely damaged by Spanish bombings in 1762 (Campos, 2009). For this reason, even though the structural

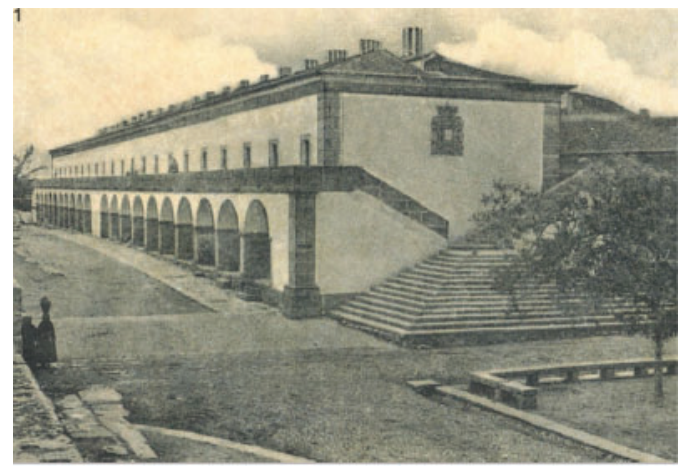

Figure 1. Old picture of the Quartel das Esquadras (Gabinete Técnico Local, 2010). system of the main body is almost the same in both levels, finding different morphologies of walls and vaults during the survey campaign was expected to be highly possible.

The load bearing walls are rendered all over the construction, but for an external bare stripe at the base of the building, which shows double-leaf walls of ashlar masonry composed by large blocks of granite with an embedded granite impost to receive the barrel vaults. Their defining qualitative characteristics are the presence of horizontal courses and parallepiped-shaped large stones, an overall good quality of mortar, the absence of aligned mortar head joints, and the lack of transversal connections. Three different types of walls were identified as being of relevance for the characterization of the structure: ground level walls, first level walls, and several other thicker walls (see Figure 2).

Results obtained from historical research and visual inspection identified the vaulted system as being composed by on-edge brick masonry vaults grouped in five different types. From among them, two types were identified as being of main relevance for the characterization of the structure: the ground floor and the first floor segmental barrel vaults, which were expected to present differences in bonding and thickness. Having all the vaults slightly different dimensions, their geometry can be defined within the same averaged values: $9.8 \mathrm{~m}$ long, covering $3.9 \mathrm{~m}$ span, and rising $1.35 \mathrm{~m}$ from the spring line up to an internal height of $3.85 \mathrm{~m}$. A heterogeneous mix of dust and debris was infilling most of the first floor vaulted system, while the infilling material of the ground floor vaults remained unknown.

The roof structure is a combination of timber and masonry elements cladded with Arabic tiles. A very characteristic feature is the presence of twelve large chimneys, remaining of the sequence of 21 chimneys that once riveted the top of the building. The chimneys arise from the ground floor, going through the segmental barrel vaults, and reach the top part of the rooftop, and their load bearing nature is yet to be clarified.

\subsection{Description of the intervention}

The introduction of an extensive variety of uses, which demand very different and specific requirements, results in the need of the structure to withstand new and diverse imposed loads. Moreover, the building typology, because of its rigid spatial distribution, lacks passages and communication systems in order to enable a proper contemporary use of the building, fulfilling architectural requirements and current

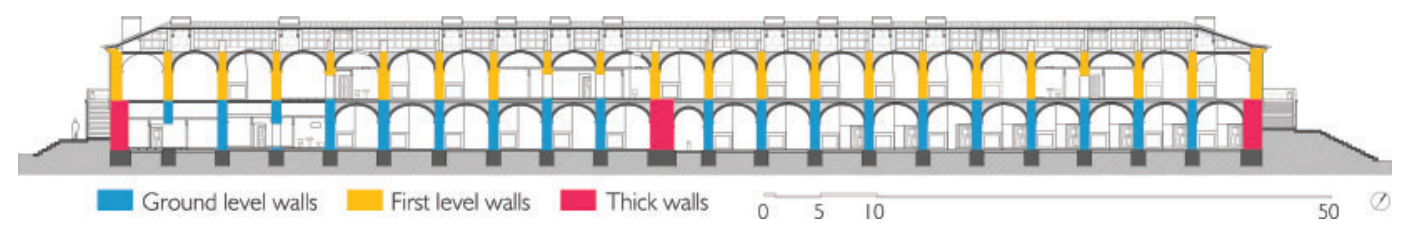

Figure 2. Identification of different types of masonry walls within the structure: W1 (ground level walls, in blue), W2 (thicker walls, in red), and W3 (first level walls, in orange). 
building codes. Therefore, the analysed intervention foresees the introduction of the required passages and communication systems for which some structural elements will have to be removed or modified, altering the current configuration of the structure (see Figure 3 ).

Certain points have been identified as possible sources of major structural problems: the influence of the addition of high live loads on top of the vaulted system of the first floor; the influence that the openings in walls and vaults might have in the overall structural safety of the building; the risk that an intervention (introduction of an elevator, wine rack and passage) in an intermediate thick wall supposes, especially considering the complete lack of information regarding its morphology; the compatibility between the proposed reinforced concrete structure and the original structure; the suitability of the designed steel lintels for their purpose; and the influence in the structural behaviour of the order in which the interventions will be performed.non-destructive testing.

\subsection{Objectives}

Since essential information for characterizing the structure was needed, and the parameters to be studied couldn't be extracted from a visual inspection, an in situ testing campaign was planned and carried out. The results from historical research and visual inspection were useful for identifying certain walls and vaults as main objectives for further characterization in order to incorporate in the most reliable way possible their real characteristics in the analysis of the capacity of the structure.

The main aspects to be investigated were the verification of the provided geometrical survey, in particular the thickness of the vaults in the ground and the first floor; the current condition of the structural elements, and the identification of damage caused by past alterations or ongoing phenomena (presence of cracks, moisture, material deterioration, and use of concrete); the presence, height and characteristics of infilling materials; the material and morphology of all identified types of walls and vaults; the mechanical properties of the masonry of the different types of walls identified; and the modal parameters of the structure.

The testing campaign comprised the application of sonic testing, ground penetrating radar and dynamic testing. The results obtained from the dynamic identification are not included in this paper because their use for verifying and complementing the rest of the collected information has not yet been done.

\subsection{Sonic transmission tests}

Analysing signals from direct tests allows the mapping of P-waves velocities, revealing information about the morphology of the wall. Analyzing velocities from indirect tests makes possible, selecting an estimated density of the masonry, an estimation of the Poisson's ratio and the Young's modulus of the corresponding leaf of the wall

Direct tests in individual stones from the exterior bare walls were performed in order to have a reference value of the propagation velocities through the granite stone, under the assumption that is the material composing the interior masonry walls. The average velocity obtained $(3351 \mathrm{~m} / \mathrm{s})$ is a reasonable value considering that the average propagation velocities of $\mathrm{P}$-waves $\left(\mathrm{V}_{\mathrm{P}}\right)$ in stones are within the range of $2000-5000 \mathrm{~m} / \mathrm{s}$.

Three walls were selected to be studied by means of sonic testing: a ground floor standard wall (W1); the ground floor thicker middle wall (W2); and a first floor standard wall (W3). All walls had both faces rendered, but for the external face of wall W2. Indirect and direct tests were carried out over a surface of $2.25 \mathrm{~m}^{2}$ in a $4 \times 4$ grid of points, separated from each other by $50 \mathrm{~cm}$ in vertical and horizontal directions (see Figure 4).

The estimation of the masonry's density, necessary for the calculation of the Young's modulus, has been based on the values recommended by the literature (NTC, 2008) for masonries with qualitative
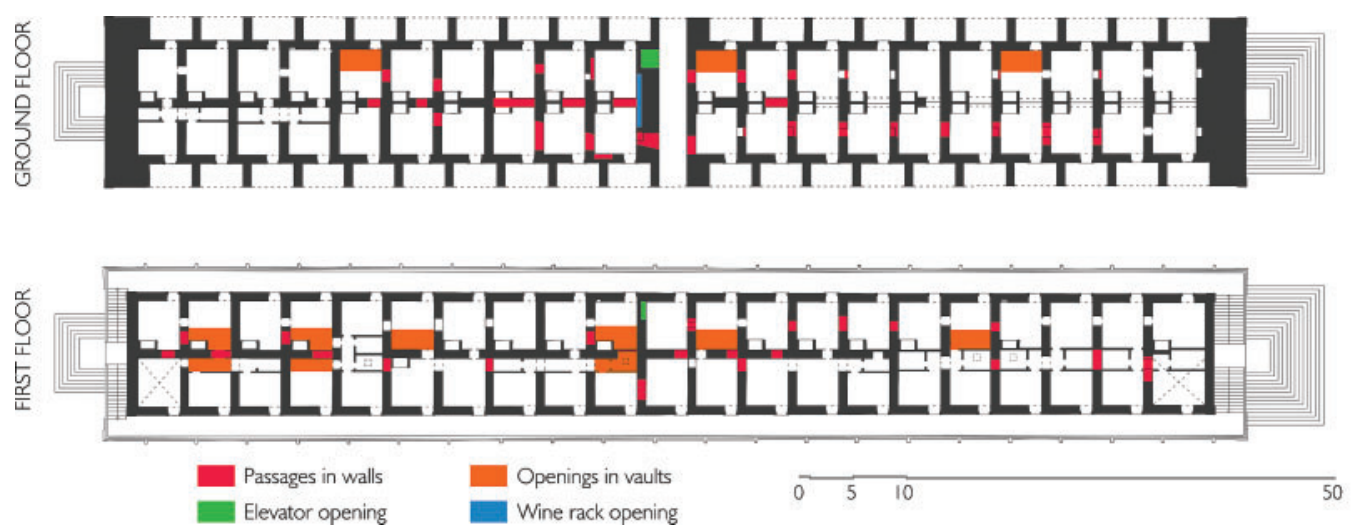

Figure 3. Distribution of openings affecting the original structure of the Quartel das Esquadras resulting from the intervention proposed by the adaptive reuse project: openings in walls (red), openings in vaults (orange), elevator opening (green) and wine rack opening (blue). 


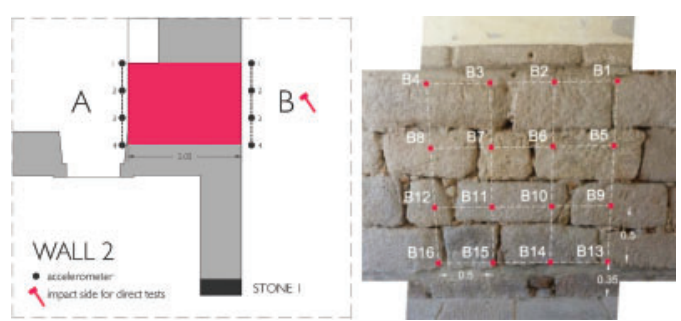

Figure 4. (left) Location plan of the sonic tests in wall W2; (right) location of the tested points in the $4 \times 4$ grid for the direct tests.

Table 1. Summary table of parameters obtained with the sonic transmission tests.

\begin{tabular}{cccc}
\hline & Wall 1 & Wall 2 & Wall 3 \\
\hline $\begin{array}{c}\text { Direct tests: } \\
\mathrm{V}_{\mathrm{P}}(\mathrm{m} / \mathrm{s})\end{array}$ & 1371 & 726 & 1095 \\
$\begin{array}{c}\text { Indirect tests: } \\
\mathrm{E}(\mathrm{GPa})\end{array}$ & 2.06 & 1.57 & 1.13 \\
\hline
\end{tabular}

characterization similar to the one described in section 1.3 . A density of $2000 \mathrm{~kg} / \mathrm{m}^{3}$, a value for a medium masonry quality, was chosen.

The obtained data, even though mainly qualitative, yielded very useful information regarding the morphology of the studied walls. The hypothesis based on historic research, that the load bearing walls might have different properties in ground and first floors, was validated. The first floor wall (W3) presents average velocities, directly related to the density, $80 \%$ the value of the ones in the ground floor wall (W1). This is also reflected in the estimated Young's modulus, which is $1.13 \mathrm{GPa}$ for wall $\mathrm{W} 1$ while a value of $2.06 \mathrm{GPa}$ is reached in wall W2 (see Table 1).

Calculations show very high values of Poisson's ratio, not fitting the reasonable values for masonry, possibly influenced by the measurements of Rayleigh wave's velocity $\left(V_{R}\right)$. For this reason, it is recommended not to use them for future structural analysis and select reference values from the literature. However, Young's moduli are within the reference values expected for historic masonry, and the values obtained match the considered hypotheses.

In general, walls have been found to present a very heterogeneous distribution of propagation velocities; especially walls W1 and W3 (see Figure 5). The extreme values could correspond to: transversal stones, because the velocity is similar to the one obtained for the reference stones; and areas with very poor masonry quality or with inner voids where the velocities are lower. Results suggest the presence of voids in the three inspected walls. This reveals that, if an increase of the mechanical properties of the wall is needed, grout injection could be considered.

The results obtained from the direct tests in wall W2, much less heterogeneous than in the case of wall W1, display much lower average values $\left(V_{P}=725 \mathrm{~m} / \mathrm{s}\right)$

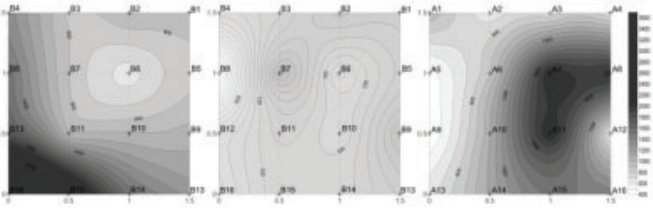

Figure 5. Sonic velocity maps obtained for the tested walls $\mathrm{W} 1, \mathrm{~W} 2$ and $\mathrm{W} 3$, in which the darker areas correspond to higher velocities.

with lower coefficients of variation than in the case of walls $\mathrm{W} 1$ and $\mathrm{W} 3$. Even if it fits into the expected values for a historic masonry wall $\left(\mathrm{V}_{\mathrm{P}}=350-2500 \mathrm{~m} / \mathrm{s}\right)$, it is a rather low value and that might be caused by a very low masonry quality, the presence of infilling material, the presence of inner voids, or a combination of some of these factors. Further investigation was needed in order to determine which cause it was.

\subsection{Analysis of sonic signals in wall W2}

By means of studying the geometrical survey, an approximated value for leaf A thickness of at least $80 \mathrm{~cm}$ could be estimated. Knowing the depth of the leaf was essential for determining an estimated cross section and a Young's modulus of the infill of the wall. For this reason, a study of the frequency content of the direct tests signals based on the approach of impact echo, a wave propagation-based technique which uses frequency domain analysis for data interpretation, was carried out. The three most representative signals of each test, the ones closer to the average value, were analysed. By identifying the higher frequencies of each signal, and considering the relation between the frequency, depth and the velocity $\mathrm{V}_{P}$, an estimative value of the depth of the leaf in each point could be calculated (see Figure 6).

Some of the signals showed less clear frequency content, maybe due to a very irregular surface of the stone (marked with dashed lines in Figure 6). Results showed an average value of $91 \mathrm{~cm}$, greatly influenced by the possible presence of larger stones in the base of the wall, which was usual practice among the stonemasons. In order to exclude the values affected by the unclear signals, results with a coefficient of variation (COV) higher than $10 \%$ were discarded and a new average value of $82 \mathrm{~cm}$ was obtained. The initial hypothesis which considered that the investigated leaf could have a depth of $80 \mathrm{~cm}$ was then validated.

Known the thickness of both leaves thanks to the sonic and GPR testing, a correlation between the propagation velocities $V_{P}$ obtained in the direct and indirect tests was done, and the propagation velocity across the infill was calculated. For guessing the Young's modulus of the infill the Equation 1 was used, obtaining a value of $0.31 \mathrm{GPa}$. This value is within the range of Young's Modulus of earthen materials, reason for which the infill of wall W2 is believed to be earth, confirming a hypothesis elaborated after finding presence of earth between two stones of one of the thicker 

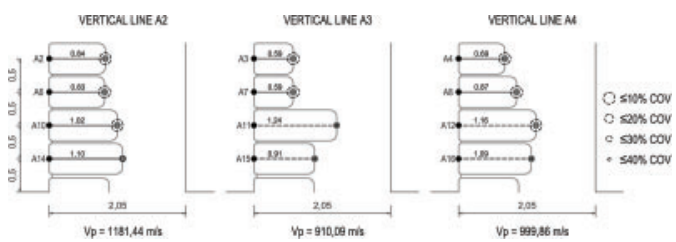

Figure 6. Possible disposition of stones in leaf A of wall W2. For each point stone, calculated values of depth in $\mathrm{m}$ and coefficient of variation are given (dashed lines indicate signals with unclear frequency content).
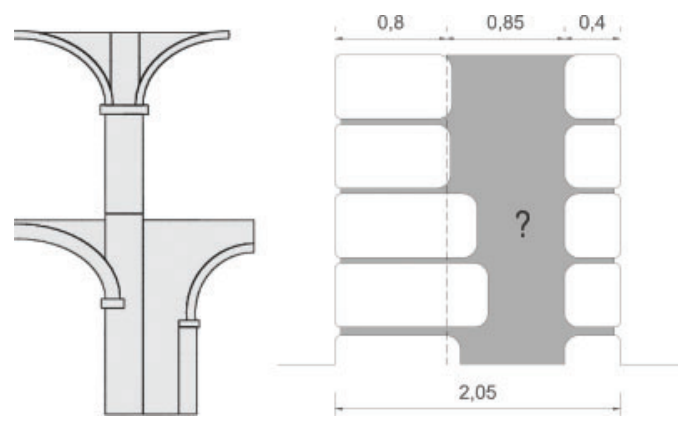

Figure 7. Possible cross sections of wall W2, in which the inner leaf has the thickness of a standard wall $(80 \mathrm{~cm})$, and the exterior leaf has a thickness of $40 \mathrm{~cm}$. The infill is most probably an earthen material.

walls during the visual inspection.

$V_{p}=\sqrt{\frac{E}{\rho} \cdot \frac{1-v}{(1+v)(1-2 v)}}$

\subsection{Ground penetrating radar}

The non-destructive nature of GPR techniques, combined with its capacity of detecting hidden properties of masonry elements, made it an evident choice in order to collect necessary information regarding the geometric and morphologic characteristics of the structure. The main aspects to be inspected were the thickness of the vaults in the ground floor; the presence, height and characteristics of infilling materials; and the morphology of all identified types of load bearing masonry walls. Based on these aspects, the areas to be investigated were chosen and the survey was carried out with medium-high frequency antennas (500 and $800 \mathrm{MHz}$ ).

A ground floor standard wall, a first floor standard wall, the ground floor thick wall and barrel vaults in both floors were inspected. The load bearing standard masonry walls have been characterized as double leaf masonry walls with transversal connectors and no rubble between the leafs, showing presence of humidity in both levels.

The survey carried out in the ground floor thicker wall (W2) revealed a thickness of the exterior leaf of the wall of approximately $40 \mathrm{~cm}$, and the presence of high contents of humidity within the section of the

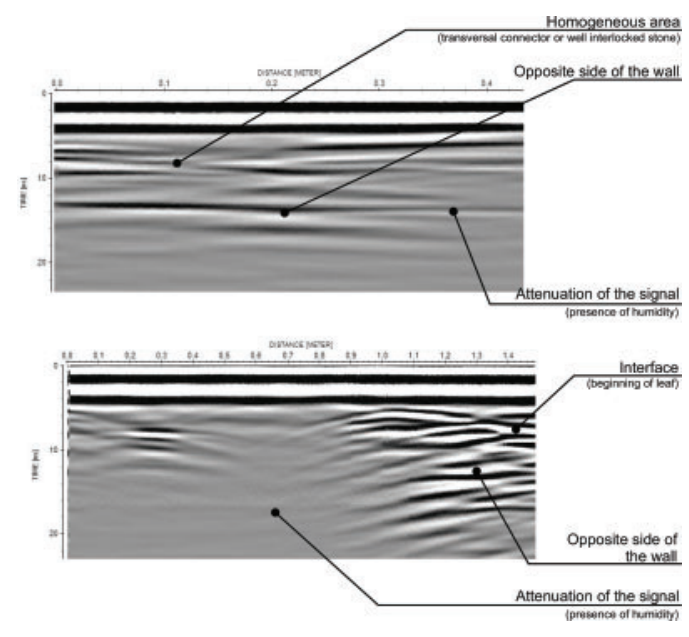

Figure 8. Radargrams obtained in first floor wall: horizontal radargram (top); and vertical radargram with the ground level at the right side of the image (bottom).

wall. The inner leaf could not be measured because of the high humidity content present in the chamber.

The comparison between the two-way travel-times across both types of vaults yielded that the ground floor vault had a thickness approximately two times the thickness of the first floor vaults, which had been previously measured in the survey campaign.

\section{STRUCTURAL ANALYSIS}

In order to study the wider range of issues possible, an area of particular relevance for the intervention was selected to generate a local model composed by solid elements, which represented three bays of both levels of masonry structure of the main body of the building: the load bearing walls, the impost line, the barrel vaults and the infill. The selected area not only presents the wider openings in the walls projected in the intervention, but also includes the ground floor thicker wall W2 and all its alterations. The safety assessment of the current and the altered state of the selected part of the structure has been studied by means of generating two models: one that simulates the current state of the building and a second altered model with the alterations to be carried out by the intervention (see Figure 9 ), and computing a sensitivity analysis by means of several non-linear static analyses.

The solid elements chosen to model the masonry structure were ten-node, three-side isoparametric solid tetrahedron elements, while the reinforced concrete beams and the elevator core introduced in the altered model were modelled using six-node triangular isoparametric plane stress shell elements. The boundary conditions at the base of the model have been considered pinned, restraining translational movements in all three directions. To incorporate the interaction and confinement with the adjacent bays, translations in the 

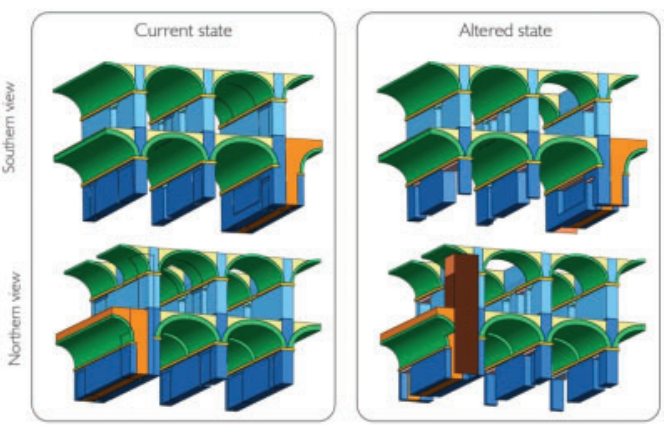

Figure 9. Different views of the partial models of the structure, on both current and altered state.

longitudinal axis have been restrained. Due to the poor connection the façade and the transversal walls might have, the contact with the façades was modeled with unrestrained nodes.

In order to simplify the model of the original structure, the roof structure was not modeled, but the loads derived from it have been evaluated and incorporated in the model; the chimneys have been taken into account by including the openings and loads associated to them; and the partition walls have been simplified as pressure loads applied over the ground floor infill, as well as the granite pavement.

For the altered state structure, the model incorporates all previous considerations with the ones associated with the intervention, namely: the material corresponding to the openings in walls and vaults has been removed; the reinforcements derived from the openings (steel lintels in walls, edge concrete beams in vaults) have been incorporated; the lintels in the partition walls have been simplified as point loads applied on the granite impost line; and the reinforced concrete elevator core has been inserted.

The findings derived from the non-destructive testing campaign have been incorporated in the material characterization, and the morphological definition of walls and vaults. Additional information regarding the definition of the structural model and the applied loads can be found at (Núñez García, 2015).

Two different approaches were adopted for the safety analysis of the selected area: firstly, a study of the influence that the proposed alterations would have on the safety of the structure was done by means of comparing the maximum load factors of the current and the altered state models. For that purpose, increments of the self-weight and live loads were successively applied to the structure. Secondly, a study of the safety of the altered state of the structure against the new imposed live loads was done by means of applying successive increments of it.

The main conclusion extracted from the comparative safety analysis is that the altered state of the structure presents a safety factor (2.00) lower than the one of the structure in its current condition (5.63). Crushing of the stone masonry at the base of the ground floors leads the structure to failure (see Figure 10).
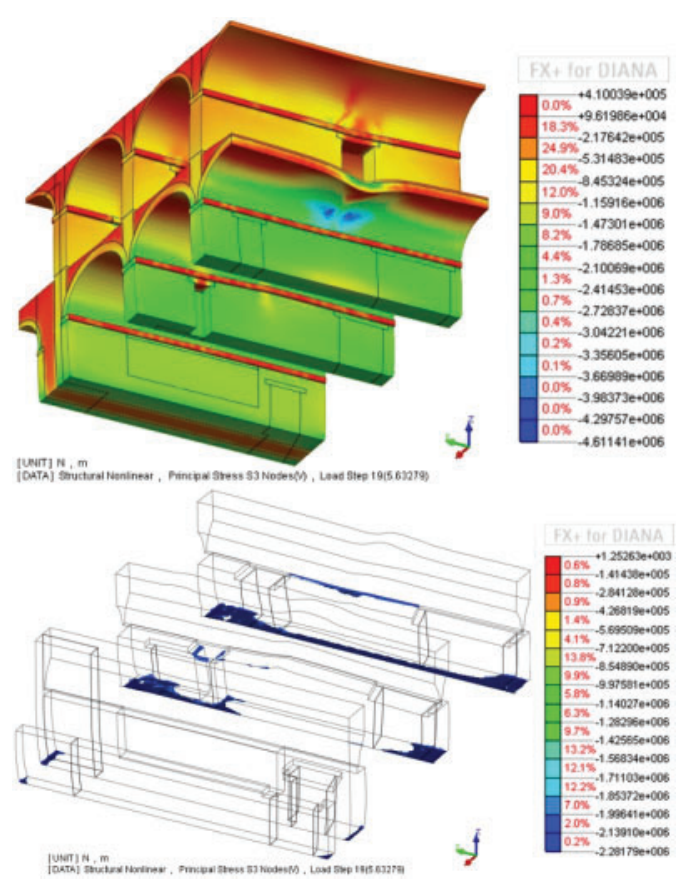

Figure 10. Stresses in the current state model depicted on deformed shape: (top) minimum principal stresses at last load step $(\mathrm{LF}=5.63)$; (bottom) detail of the ground floor walls showing the minimum principal stresses over the compressive strength of the stone masonry $(2.0 \mathrm{MPa})$ in the last load step $(\mathrm{LF}=5.63)$.

In the safety analysis of the altered state model against live loads, a maximum load factor equal to 3.4 has been reached for a vertical load associated to the archive on the top floor of $5 \mathrm{kN} / \mathrm{m}^{2}$.

In the three different analyses, the crushing of the stone masonry walls at the base of the ground floor led the structure to failure, pointing them as the weakest point of the structure. In case of the altered state models, the obtained safety factor was reasonably lower because the increment of live loads and the execution of the openings performed in the walls aggravated the condition of the ground floor walls. Therefore, it can be stated that the intervention in the structure has decreased its capacity of withstanding loads. It can be recommended that, in the case that an increase on the load bearing capacity of the structure was needed, either in current or altered condition, the ground floor walls would be the structural element whose mechanical characteristics should be improved, particularly in the vicinity of the openings.

While carrying out the analyses, it has been discerned that determining if the chimneys are or not self-supported highly influences the results of the analyses. In the first generated models, the chimneys were considered as supported on the rest of the structure. The obtained results showed local failures on the edge of the vault, right below the loads, and the obtained load factors were much lower than the analysis without 


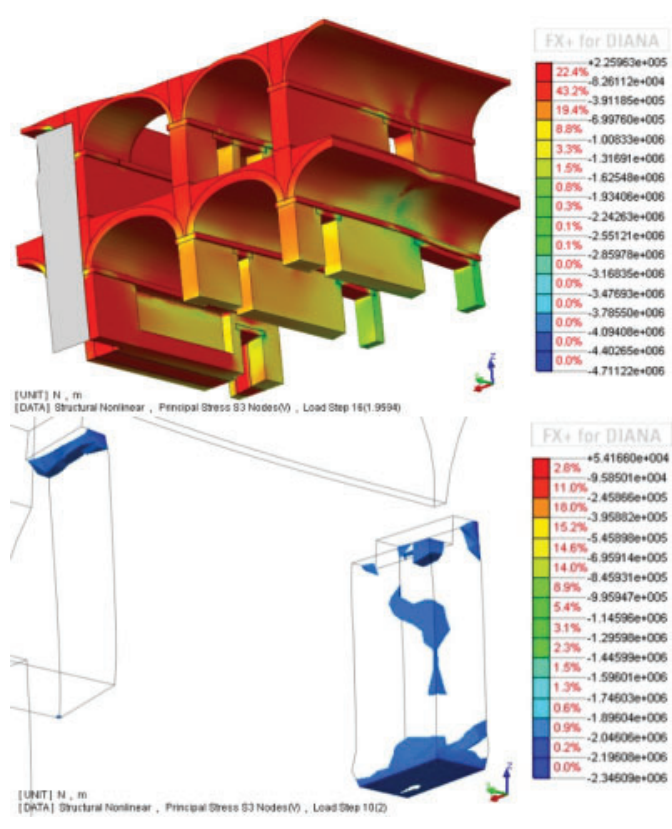

Figure 11. Stresses in the altered state model depicted on deformed shape: (top) minimum principal stresses at the highest load factor $(\mathrm{LF}=2.0)$; (bottom) detail of affected pier showing the minimum principal stresses over the compressive strength of their stone masonry $(2.0 \mathrm{MPa})$, at highest load factor applied $(\mathrm{LF}=2.0)$.

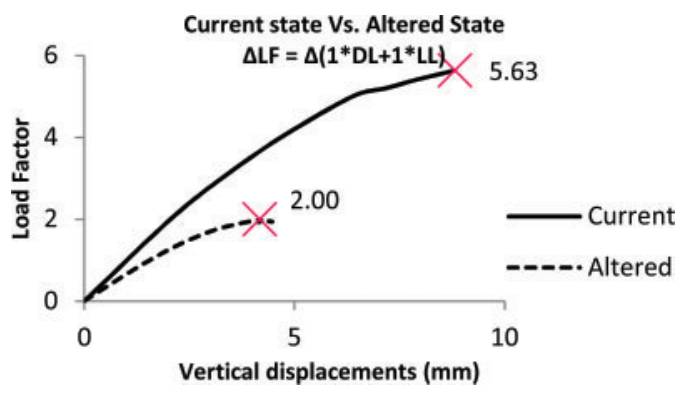

Figure 12. Load-displacement diagrams of the current and the altered state of the structure, plotted for the point with maximum vertical displacement in each case.

the chimneys. In order to better study a more general failure of the structure, the final models presented in this document were analysed under the assumption of having self-supported chimneys. Nevertheless, further investigation on the connection of the chimneys with the rest of the structure is needed, as it is crucial for a proper interpretation of the obtained results.

Regarding the inserted reinforcements, results from the analysis suggest that compatibility problems will not arise from the insertion of the elevator and the concrete beams, as long as the live load factor does not increase over 2 . The wine rack integrated in the thicker wall does not show any critical point, but it is important to take into consideration that, in the model, it was being executed in a hypothetical $80 \mathrm{~cm}$ masonry leaf. If the cross section of the inner leaf is thinner in the area to be excavated, problems during the construction process might appear. For this reason, even though the structural analysis shows no damage due to the insertion of the wine rack, an impact-echo survey is recommended to define the depth of the inner masonry leaf in the exact area to be intervened, prior to the execution of the opening. The steel lintels designed in the structural project do not show any problems in withstanding the imposed loads, but they will cause a higher concentration of stresses in the masonry piers. Increasing the bearing length of the steel lintels would help reduce the stress concentrations in their supports.

\section{CONCLUSIONS}

This paper presents an interdisciplinary scientific approach to the evaluation of the structural interventions derived from the ongoing adaptive reuse project of the Quartel das Esquadras. The safety of the studied area of the structure has been proven to be diminished by the interventions proposed in the project, but the structure in its altered condition has been verified to withstand its loading condition within a reasonable safety margin. The damage mechanism leading the structure to failure has been identified as being the same in the current and altered condition of the structure: crushing of the ground floor stone masonry walls at their base. Therefore, the ground level walls have been determined to be the most vulnerable point of the structure, whose mechanical properties should be increased in the case that higher load bearing capacity of the structure was necessary. As sonic tests showed a remarkable presence of voids within the cross section of the walls, lime-based grout injections could be a feasible solution.

Research on the morphology and certain mechanical properties of the masonry walls and vaults was necessary. For this purpose, a combined interpretation of data collected in the visual inspection and the testing campaign was proven to be of extreme importance, as each technique provided limited information about the properties of the structure, but they complemented each other in such way that estimating the quality of the masonry elements was possible.

In order to increase the level of knowledge regarding the morphology of the walls, impact echo and sonic tomography could be performed in those areas in which more precise information could be needed, such as where the wine rack is going the be built. In order to validate the material properties that have been estimated by means of sonic tests, verifications could be done by performing additional testing campaigns. Flat-jack tests and coring would yield more accurate results, and they can be performed in the areas to be demolished, keeping unaltered the structure that is not going to be intervened.

Further structural analysis would be useful not only for evaluating the structural behaviour in other areas of the building, but also for characterizing in a more accurate way the material properties of the structural 
elements. Several types of analyses would have an interesting application to the Quartel das Esquadras.

An update of the material properties could be done by calibrating a finite element model using the collected experimental modal parameters. Parametric analysis could be performed in order to extract the influence that the different properties of the material might have in the structural response.

\section{ACKNOWLEDGEMENTS}

This work was carried on the scope of the protocol between the University of Minho and the City Council of Almeida, towards the study and preservation of Almeida Fortress' constructions. The authors would like to express their gratitude to the City Council of Almeida, for providing conditions to carry out the in situ works. A special acknowledgement goes to Architect João Marujo and Architect João Campos.

\section{REFERENCES}

Campos, J. 2009. Almeida, candidatura das fortificações abaluartadas da Raia Luso-Espanhola a património mundial - UNESCO. Almeida: Câmara Municipal de Almeida.

Gabinete Técnico Local, 2010. Caracterização do património edificado. Edificio do Quartel das Esquadras. In Plano de Conservação e recuperação do Centro Histórico de Almeida. Almeida: Câmara Municipal de Almeida.

Ministerio delle Infraestrutture. 2008. Norme Techniche per le construzione e circolareesplicativa. Roma.

Núñez García, A.C. 2015. Evaluation of structural intervention in the Quartel das Esquadras, Almeida (Portugal). MSc Thesis. University of Minho, Portugal. 